\title{
Adenovirus-mediated interleukin 21 gene transfer enhances antitumor immunity and reduces tumorigenicity of Hepa1-6 in mice
}

\author{
JIYU JU $^{1}$, LINA WANG ${ }^{1}$, DALIN DI ${ }^{1}$, WEILING XIAO ${ }^{1}$, MEIYU PENG ${ }^{1}$, \\ YISHUAI LIU $^{1}$, XIAOYAN FU ${ }^{1}$, CHUNLING ZHAO ${ }^{2}$ and XUEBIN QIN ${ }^{1}$ \\ ${ }^{1}$ Department of Immunology; ${ }^{2}$ College of Pharmacy and Biological Science, Weifang Medical University, \\ Weifang, Shandong 261053, P.R. China
}

Received June 30, 2015; Accepted August 19, 2016

DOI: $10.3892 / \mathrm{ol} .2016 .5140$

\begin{abstract}
In the present study, adenovirus-mediated interleukin 21 (Ad5-IL-21-EGFP) gene expression was induced in Hepa1-6 cells to investigate whether IL-21 was capable of enhancing antitumor immunity and reducing tumorigenicity of Hepa1-6 in a mouse model. Mice were inoculated intradermally into the right flank with Hepa1-6 cells or Hepa1-6 cells infected with Ad5 or Ad5-IL-21. Four weeks later, the mice were sacrificed humanely, and the tumor volume, tumor weight and mouse spleen index were measured. The levels of IL-21, IL-4 and interferon (IFN)- $\gamma$ levels in mouse serum and tumor tissues were detected by enzyme-linked immunosorbent assay (ELISA) and immunohistochemistry. Cell counting kit-8 (CCK-8) assay was used to detect the killing ability of spleen T cells and natural killer (NK) cells, and the proliferation ability of T cells. The expression of IL-21 was confirmed by reverse transcription-polymerase chain reaction, western blot analysis and ELISA assay in Ad5-IL-21-EGFP-infected Hepa1-6 cells. The overexpression of IL-21 significantly reduced the tumorigenicity of Hepa1-6 cells. The tumor volumes and tumor weights in Ad5-IL-21-Hepa1-6 mice were much smaller than those in the Ad5-Hepa1-6 group and Hepa1-6 wild-type group. The immunohistochemistry and ELISA assay demonstrated that IL-21 and IFN- $\gamma$ levels were much higher while the IL-4 level was much lower in the Ad5-IL-21-Hepa1-6 group than in the other two groups. CCK-8 assay revealed that the killing ability of NK cells and T cells, and the proliferation ability of T cells in Ad5-IL-21-Hepa1-6 mice were higher than in the other two groups; the spleen index of Ad5-IL-21-Hepa1-6
\end{abstract}

Correspondence to: Dr Lina Wang, Department of Immunology, Weifang Medical University, Room 421, Science and Technology Building C, 7,166 Baotong Street, Weifang, Shandong 261053, P.R. China

E-mail: wln@wfmc.edu.cn

Key words: interleukin 21, antitumor immunity, tumorigenicity of Hepa1-6, liver cancer mice was also higher than in the other groups. The data had a significant difference $(\mathrm{P}<0.01)$. In conclusion, IL-21 reduces tumorigenicity of Hepa1- 6 by a mechanism involving enhanced activation of cell-mediated immunity in tumor-bearing mice.

\section{Introduction}

Interleukin 21 (IL-21), a cytokine identified in 2000 (1), is mainly secreted by activated $\mathrm{CD} 4^{+} \mathrm{T}$ cells and NK T cells $(2,3)$. It effectively enhances $\mathrm{T}$ cell proliferation and the killing function of NK cells, resulting in a strong antitumor immune response $(4,5)$. Its receptor (IL-21R) is widely expressed in various cell types within the immune system, including NK cells, B cells, T cells, macrophages and dendritic cells (6-8). The widespread lymphoid distribution of the IL-21R leads to pleiotropic action of IL-21 in the innate and adaptive immune responses (6-8). For this reason, researchers are becoming increasingly interested in IL-21. Studies have suggested that IL-21 is capable of suppressing growth in certain tumors, and it has already been used in phase I or II trials of patients with melanoma and renal cell carcinoma, with promising antitumor results obtained $(9,10)$. However, IL-21 may also promote growth in certain other tumors, including colitis-associated colorectal cancer by impairing tumor immunosurveillance (11). Therefore, the function of IL-21 is extremely complex, as its use in different cancers has been shown to lead to different results (9-11). Further research is required to investigate this notable cytokine.

Primary hepatic carcinoma (PHC) is currently the fourth most common cause of cancer-related mortality worldwide (12). Its incidence is rapidly increasing (13). To date, there have been no in-depth studies into the use of IL-21 in PHC. In the present study, we used adenovirus-mediated IL-21 gene expression in the mouse hepatic cancer cell line Hepa1-6 to investigate the influence of IL-21 on antitumor immunity and tumorigenicity in mice, with the aim of identifying a novel biological treatment for PHC.

\section{Materials and methods}

Materials. Murine hepatocellular carcinoma Hepa1-6 cells and the murine T-lymphoma YAC-1 cell line sensitive to NK cells 
were obtained from the Immunology Laboratory of Weifang Medical University (Weifang, China). Mouse hepatoma carcinoma cell line Hepa1-6 cells were maintained in Dulbecco's modified Eagle medium (DMEM; Sigma-Aldrich, St. Louis, MO, USA) supplemented with $10 \%$ fetal bovine serum (FBS) and $1 \%$ penicillin/streptomycin solution. YAC-1 cells were maintained in RPMI-1640 (Gibco; Thermo Fisher Scientific, Inc., Waltham, MA, USA) supplemented with 10\% FBS and $1 \%$ penicillin/streptomycin solution. The cell counting kit- 8 (CCK-8) was purchased from Beyotime Institute of Biotechnology (Haimen, China).

A replication-defective recombinant Ad5 vector encoding mouse IL-21 (named Ad5-IL-21-EGFP) and a replication-defective recombinant Ad5 vector (named Ad5-EGFP) were purchased from Vector Gene Technology Company Ltd. (Beijing, China). The physical titer of the recombinant virus $\left(\mathrm{vp} / \mathrm{ml}\right.$ ) was $5.3 \times 10^{11}$, and the infectious titer (TCID50/ml) was $4 \times 10^{10}$.

SPF male C57BL/6 mice (6-8 weeks old) were purchased from the Vital River Laboratory Animal Technology Co. Ltd. (Beijing, China). The present study was approved by the ethics committee of Weifang Medical University.

Preparation of spleen mononuclear cells. The mouse spleen was removed and weighed in a sterile manner. Single spleen cell suspension was prepared by passing through nylon mesh (200-mm pore size; BD Biosciences, Baltimore, MD, USA) with a sterile rubber spatula. Mononuclear cells were obtained by Ficoll-Hypaque density methods. Briefly, 3-4 ml spleen cell suspension was added slowly on the surface of the Ficoll along the tube's wall (so as not to break the interface), then balanced and centrifuged at $2000 \mathrm{x}$ g for $20 \mathrm{~min}$. Mononuclear cells were carefully transferred into another tube. Following further washes with phosphate-buffered saline (PBS), the cells were re-suspended in complete RPMI-1640 supplemented with $10 \%$ (v/v) heat-inactivated FBS (Gibco; Thermo Fisher Scientific, Inc.) and antibiotics (100 IU/ml penicillin, $100 \mathrm{mg} / \mathrm{ml} \mathrm{strep-}$ tomycin).

Establishment of cell lines. Hepa1-6 cells seeded $24 \mathrm{~h}$ earlier were infected with Ad5-EGFP or Ad5-IL-21-EGFP in serum-free DMEM for $2 \mathrm{~h}$, then the infection medium was replaced with normal medium. The infection efficiency was assessed by fluorescence microscopy $24 \mathrm{~h}$ later. The Hepa1-6 cell line infected with Ad5-EGFP was named Ad5-Hepa1-6, and the Hepa1-6 cell line infected with Ad5-IL-21-EGFP was named Ad5-IL-21-Hepa1-6.

After cells had been infected with Ad5-IL-21-EGFP or Ad5-EGFP for $24 \mathrm{~h}$, cell culture supernatant was collected to measure the IL-21 expression level using the mouse IL-21 enzyme-linked immunosorbent assay (ELISA) Ready-SET-Go kit (eBioscience, San Diego, CA, USA). Next, total cellular RNA of certain cells was extracted using TRIzol reagent (Invitrogen Life Technologies, Carlsbad, CA, USA) and reverse transcription was carried out by converting $0.5 \mu \mathrm{g}$ RNA into complementary DNA (cDNA) using the iScript ${ }^{\mathrm{TM}}$ cDNA synthesis kit (Bio-Rad Laboratories, Inc., Hercules, CA, USA). The target gene was amplified by polymerase chain reaction (PCR) using the GreenTaq ${ }^{\mathrm{TM}}$ Ready Mix PCR reaction mix (Sigma-Aldrich). The following primers were used: forward, 5'-CCGCTAGCCTGGAGACTCAGTTCTG-3'; and reverse, 5'-CCCAAGCTTCTAGGAGAGATGCTGATG-3'. Certain cells were washed with pre-cooled PBS twice, and lysed in RIPA buffer containing proteinase inhibitor cocktail on ice. The protein sample was quantified using a Bio-Rad DC protein assay kit (Bio-Rad Laboratories, Inc.; catalog no. 500-0114). Total protein samples were separated by $12 \%$ sodium dodecyl sulphate-polyacrylamide gel electrophoresis prior to electrophoretic transfer to a nitrocellulose membrane. Western blot analysis was carried out in pre-cooled transferring buffer at $100 \mathrm{~mA}$ for $1 \mathrm{~h}$. The nitrocellulose membrane was then blocked in 5\% milk in Tris-buffered saline with $0.05 \%$ Tween-20 solution. The membrane was then incubated with rat anti-mouse IL-21 mAbs (Peprotech 500-p278) at $4{ }^{\circ} \mathrm{C}$ overnight. After washing three times with PBS with $0.05 \%$ Tween-20 (PBST), the membrane was incubated with horseradish peroxidase-conjugated goat anti-rat antibody for $2 \mathrm{~h}$ at room temperature. The membrane was then washed five times with PBST and developed using a chemiluminescence detection kit (Sangon Biotech, Co., Ltd., Shanghai, China). The target protein bands were detected following exposure of the membranes to X-ray film and $\beta$-actin was used as an internal control.

Establishment of tumor model. For the subcutaneous Hepa1-6 tumor model, Ad5-Hepa1-6, Ad5-IL-21-Hepa1-6 and Hepa1-6 wild type (WT) were washed with sterilized PBS twice, then the cell density was adjusted to $1 \times 10^{7} / \mathrm{ml}$. Cell suspension $(100 \mu \mathrm{l})$ was inoculated intradermally into the right flank of each mouse. Each group contained four mice, and the studies were repeated three times. Four weeks later, tumors were removed and weighed, and the tumor length and width were measured with calipers after the mice had been sacrificed in a humane manner. The tumor volume (in $\mathrm{mm}^{3}$ ) was estimated using the standard formula: tumor volume $\left(\mathrm{mm}^{3}\right)=$ length $\mathrm{x}$ width ${ }^{2} \mathrm{x} 0.5$. Mouse serums were separated and stored at $-70^{\circ} \mathrm{C}$ for cytokine detection. Mouse tumor tissues were weighed following sacrifice and fixed in formaldehyde for immunohistochemistry. The mouse spleen and body were weighed in order to estimate the spleen index using the standard formula: spleen index $=$ spleen weight (mg) / mouse weight (g).

Assessment of IL-21, IL-4 and interferon (IFN)- $\gamma$ levels by immunohistochemistry. IL-21, IL- 4 and IFN- $\gamma$ levels in mouse serum were detected using the ELISA Ready-SET-Go kit as described previously. Proteins expressed in the mouse tumor tissues were detected by immunohistochemistry, which was performed on serial $4-\mu$ m-thick paraffin sections. The slides were deparaffinized in xylene and re-hydrated through four decreasing grades of ethanol $(100,95,80$ and $70 \%)$ for $2 \mathrm{~min}$ each. Endogenous peroxidase activity was blocked by immersing the slides in 3\% hydrogen peroxide in methanol for $15 \mathrm{~min}$ at room temperature. Heat-induced antigen retrieval was performed for 5 min with $1 \mathrm{X}$ citrate buffer $(\mathrm{pH} \mathrm{6.3)} \mathrm{in}$ a microwave and then cooled for $5 \mathrm{~min}$. This process was performed three times. To reduce the nonspecific binding of antibodies to the tissues, the slides were pre-incubated with blocking serum in $1 \%$ bovine serum albumin for $30 \mathrm{~min}$ at room temperature. They were left to incubate with rabbit polyclonal anti-IL21, IL-4 and IFN- $\gamma$ (antibody dilution, 1:200), 
respectively, overnight at $4^{\circ} \mathrm{C}$. Following incubation with the primary antibodies, the slides were rinsed with PBS for 10 min. Chromogen was then for the detection of the antibody reactions. The color was developed using diaminobenzidine. Finally, the sections were counterstained with Mayer's hematoxylin solution for $1 \mathrm{~min}$, and dehydrated with graded alcohols, dipped in two changes of xylene, and mounted.

$T$ cell proliferation assay. The proliferation of $\mathrm{T}$ lymphocytes was observed using CCK-8 assay. Briefly, the spleen mononuclear cells were adjusted to a final concentration of $1 \times 10^{7}$ cells $/ \mathrm{ml}$ in complete RPMI-1640 medium. The cell suspensions were added to 96 -well plates (100 $\mu \mathrm{l} /$ well) in triplicate, and another medium (100 $\mu \mathrm{l} /$ well) containing $40 \mathrm{mg} / \mathrm{ml}$ concanavalin A (Sigma-Aldrich) was added. Medium was also added to another triplicated well as a control. Following incubation for $72 \mathrm{~h}, 20 \mu \mathrm{l}$ CCK-8 was added to each well and the plate was incubated for an additional $2 \mathrm{~h}$ at $37^{\circ} \mathrm{C}$. The absorbance at $450 \mathrm{~nm}$ of each aliquot was determined using a microplate reader. The stimulation index was calculated as a percentage of the absorbance in treated wells relative to the absorbance in untreated (control) wells.

T lymphocyte and NK cell killing ability assay. Effector cells generated from spleen mononuclear cells from Ad5-IL-21-Hepa1-6, Ad5-Hepa1-6 and Hepa1-6 mice were mixed with the target cell Hepa1-6 (for T lymphocyte killing assay) or YAC-1 (for NK cell killing assay) at a ratio of 20:1 in triplicated wells and incubated for $4 \mathrm{~h}$ in 96 -well plates. The target cell control and effector cell control were plated in triplicate. Cells were incubated for $3 \mathrm{~h}$ after CCK- 8 reagent was added to the mixture $(20 \mu \mathrm{l} /$ well $)$. Finally, the optical density (OD) value of each well was measured by the microplate reader at a wavelength of $450 \mathrm{~nm}$. The cytotoxic activity of the effector cells was determined using the standard formula: killing rate $(\%)=1-(\mathrm{OD}$ value of experimental well $-\mathrm{OD}$ value of effector cell control) / OD value of target cell control. The killing rates among the three groups were compared.

Statistical analysis. All the data were analyzed with SPSS 11.5 (SPSS, Inc., Chicago, IL, USA). Statistical comparisons were performed by one-way analysis of variance. $\mathrm{P}<0.05$ was considered to indicate a statistically significant difference between data.

\section{Results}

Establishment of cell lines. The expression of EGFP reporter genes was analyzed $24 \mathrm{~h}$ after infection. Fluorescence microscopy analysis confirmed EGFP expression in cells infected with Ad5-EGFP and Ad5-IL-21-EGFP (Fig. 1A). Reverse transcription-polymerase chain reaction confirmed the expression of IL-21 mediated by Ad5-IL-21-EGFP at the RNA level (Fig. 1B). Significant amounts of IL-21 expression were observed in the Ad5-IL-21-Hepa1-6 cells. Ad5-Hepa1-6 and Hepa1-6 cells were not amplified. Western blot analysis revealed IL-21 expression in Ad5-IL-21-Hepa1-6 cells (Fig. 1C), but no band was detected in Ad5-Hepa1-6 and Hepa1-6 cells. IL-21 expression in the cell culture supernatant of Hepa1-6 infected with Ad5-IL21-EGFP was detected by the ELISA method (Fig. 1D).
IL-21 significantly reduces Hepal-6 tumorigenicity. The subcutaneous tumor mouse model revealed that IL-21 significantly reduced the tumorigenicity of Hepa1-6. In the Ad5-IL-21-Hepa1-6 group, only one of the four mice grew an extremely small tumor, while in the other two groups all four mice grew larger tumors. The tumor volumes of the Ad5-IL-21-Hepa1-6, Ad5-Hepa1-6 and Hepa1-6 WT group mice were $0.008 \pm 0.015 \mathrm{~cm}^{3}, 0.677 \pm 0.208 \mathrm{~cm}^{3}$ and $0.716 \pm 0.335 \mathrm{~cm}^{3}$, respectively, and the tumor weights were $0.011 \pm 0.022 \mathrm{~g}, 0.772 \pm 0.080 \mathrm{~g}$ and $0.828 \pm 0.486 \mathrm{~g}$, respectively (Fig. 2A and B). The tumor volume and weight in the IL-21-Hepa1-6 group were much smaller than those in the other two groups, and the difference was significant $(\mathrm{P}<0.01)$.

IL-21 enhances antitumor immunity in tumor-bearing mice. Immunohistochemistry confirmed that IL-21 and IFN- $\gamma$ levels were much higher in Ad5-IL-21-Hepa1-6 mouse tumor tissues than in the other two groups, but IL-4 levels were much lower in Ad5-IL-21-Hepa1-6 mouse tumor tissues than the other two groups (Fig. 3A). Similar results were observed in the ELISA assay (Fig. 3B), which confirmed the cytokine IL-21 levels in Ad5-IL-21-Hepa1-6 mice serum to be $80.092 \pm 5.560 \mathrm{ng} / \mathrm{ml}$; much higher than those of the Ad5-Hepa1-6 group and Hepa1-6 WT groups. IFN- $\gamma$ levels were $50.464 \pm 5.679 \mathrm{ng} / \mathrm{ml}$, much higher than those of the Ad5-Hepa1-6 and Hepa1-6 WT groups, which were $15.49 \pm 2.290 \mathrm{ng} / \mathrm{ml}$ and $8.58 \pm 1.678 \mathrm{ng} / \mathrm{ml}$, respectively. IL-4 levels in Ad5-IL-21-Hepa1-6 mouse serum were $1.41 \mathrm{ng} / \mathrm{ml} \pm 0.692$, much lower than those in the Ad5-Hepa1-6 and Hepa1-6 WT groups, which were $10.843 \pm 1.398 \mathrm{ng} / \mathrm{ml}$ and $16.998 \pm 1.046 \mathrm{ng} / \mathrm{ml}$, respectively.

The spleen cell killing assay revealed the killing ability of NK and T cells in the Ad5-IL-21-Hepa1-6 mice to be $66.61 \pm 3.230$ and $82.46 \pm 6.531 \%$, respectively, which was much higher than in the Ad5-Hepa1-6 and Hepa1-6 WT groups (Fig. 3C). T cell proliferation assay revealed that the stimulation index of spleen $\mathrm{T}$ cells in Ad5-IL-21-Hepa1-6 mice was $3.1 \pm 0.261$, which was much higher than that of the Ad5-Hepa1-6 and Hepa1-6 WT groups, which were $1.45 \pm 0.266$ and $1.37 \pm 0.072$, respectively (Fig. 3D). The spleen index of Ad5-IL-21-Hepa1-6 mice was 10.22 \pm 1.329 , which was much higher than that of the Ad5-Hepa1-6 and Hepa1-6 WT groups, which were 5.5 \pm 0.519 and 4.8 \pm 0.271 , respectively (Fig. 3E).

\section{Discussion}

As a promising cytokine for cancer immunotherapy, whilst IL-21 suppresses growth in certain tumors, including renal cell carcinoma and melanoma $(9,14)$, it may promote growth in others, including colitis-associated colorectal cancer and follicular lymphoma $(11,15)$. The function of IL-21 is complex, as it appears to have different functions in different tumors.

PHC is currently the fourth-leading cause of cancer-related mortality (12), and its incidence is rapidly increasing (13). In a previous study, Pan et al (16) used the naked plasmids pmIL-21 and/or psPD-1 for local gene transfer by injection into experimental H22 murine hepatocarcinoma. The immunotherapy with IL-21 in combination with SPD-1 was observed to induce antitumor immune response. Cheng et al (17) injected 


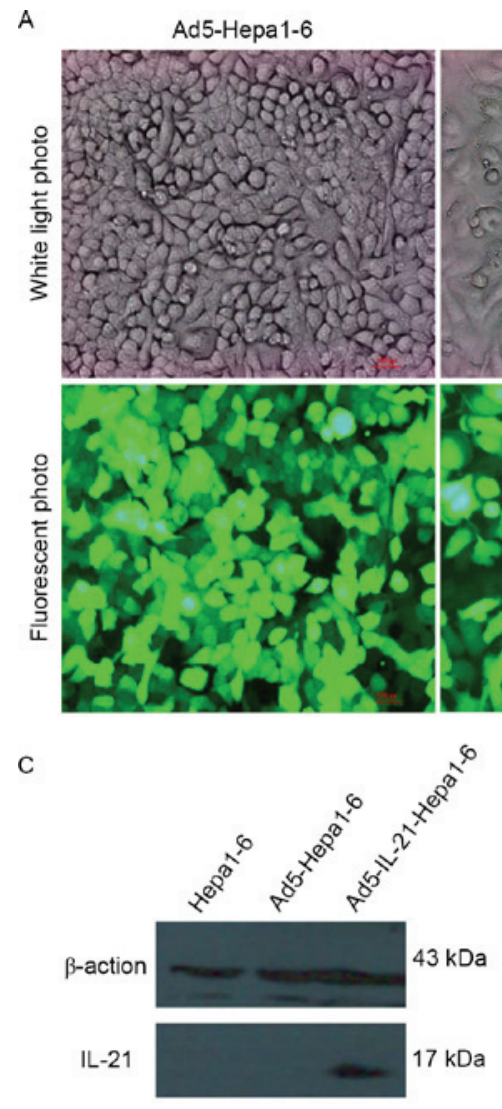

Ad5-IL-21-Hepa1-6
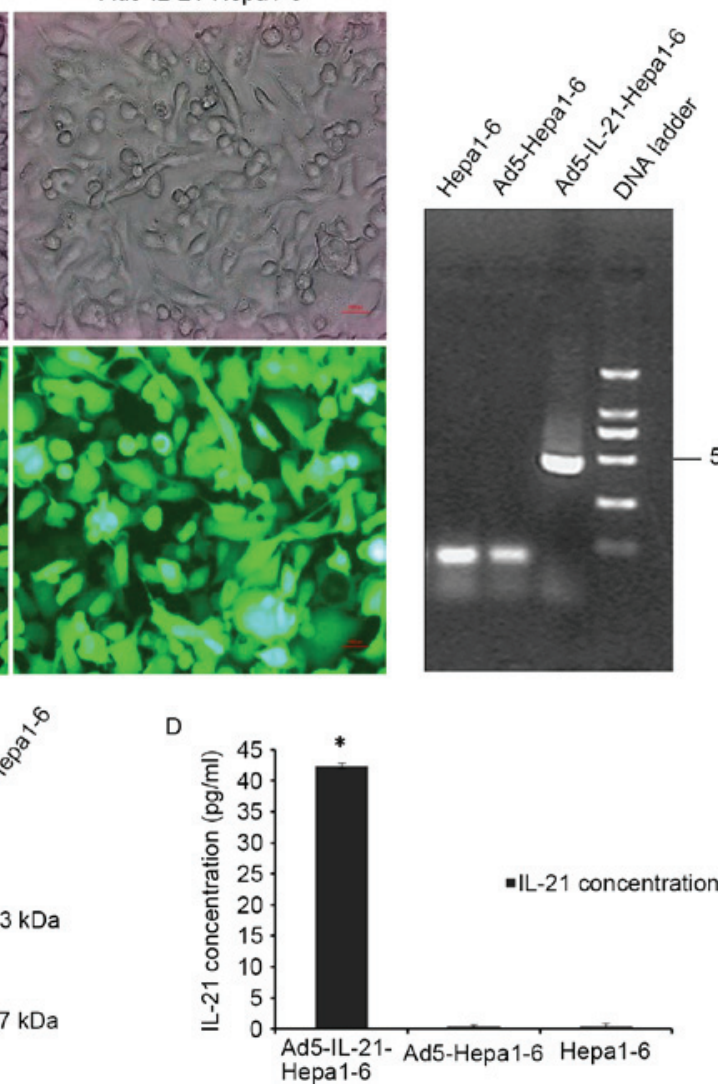

Figure 1. Adenovirus-mediated interleukin 21 (IL-21) expression in Hepa1-6 cells. (A) Fluorescence microscopy analysis reveals that Hepa1-6 cells had an extremely high infection rate of almost 100\% with Ad5-EGFP and Ad5-IL-21-EGFP. Magnification, x400. (B) Reverse transcription-polymerase chain reaction confirmed IL-21 expression in Ad5-IL-21-Hepa1-6 cells. (C) Western blot assay confirmed IL-21 expression in Ad5-IL-21-Hepa1-6 cells. (D) Enzyme-linked immunosorbent assay assay confirmed IL-21 expression in the cell culture supernatant of Ad5-IL-21-Hepa1-6 cells, but there was almost no expression in Ad5-Hepa1-6 or Hepa1-6 WT cells. Data were calculated from duplicated wells. "P<0.05, compared with Ad5-Hepa1-6 and Hepa1-6 wild-type cells.

A

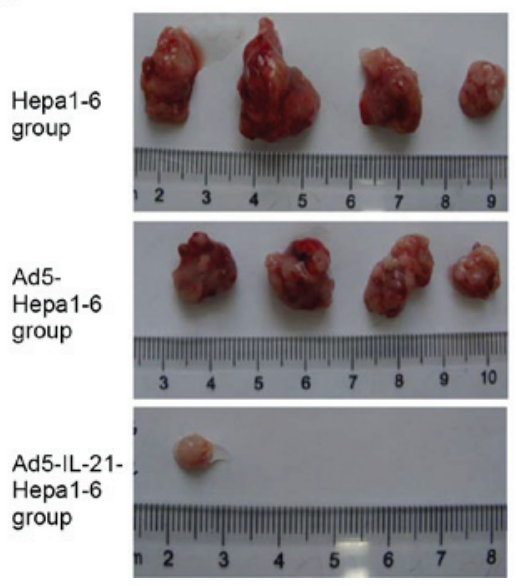

B

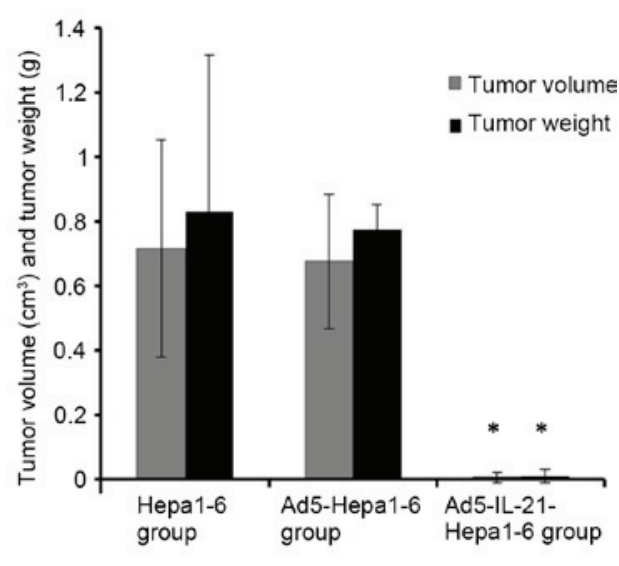

Figure 2. Tumor volume and weight in the mouse model. (A) The tumor specimens suggested that the tumorigenicity of the Ad5-IL-21-Hepa1-6 group was significantly reduced. (B) The tumor volume and weight of the Ad5-IL-21-Hepa1-6 group were significantly smaller than those of the other two groups. Data were calculated from four mice. " $\mathrm{P}<0.05$, compared with the Ad5-Hepa1-6 and Hepa1-6 groups.

recombinant plasmid capable of co-expressing GM-SCF, IL-21 and Rae-1 into a H22 cell-bearing mouse, and the recombinant expression plasmid inhibited liver cancer by a mechanism that involved activation of cell-mediated immunity in liver cancer. However, the efficiency of gene expression by naked plasmid injection was limited, and the therapeutic effect requires improvement. At present, no other study has investigated whether IL-21 is able to prevent liver cancer, and there is no available vaccine, so further study is required in this field. In the present study, we used adenovirus-mediated transfection of the IL-21 gene in the hepatic cancer cell line Hepa1-6 and investigated the effect of IL-21 on the tumorigenicity of Hepa1-6 and the influence of IL-21 on antitumor immunity in a mouse model. 
A
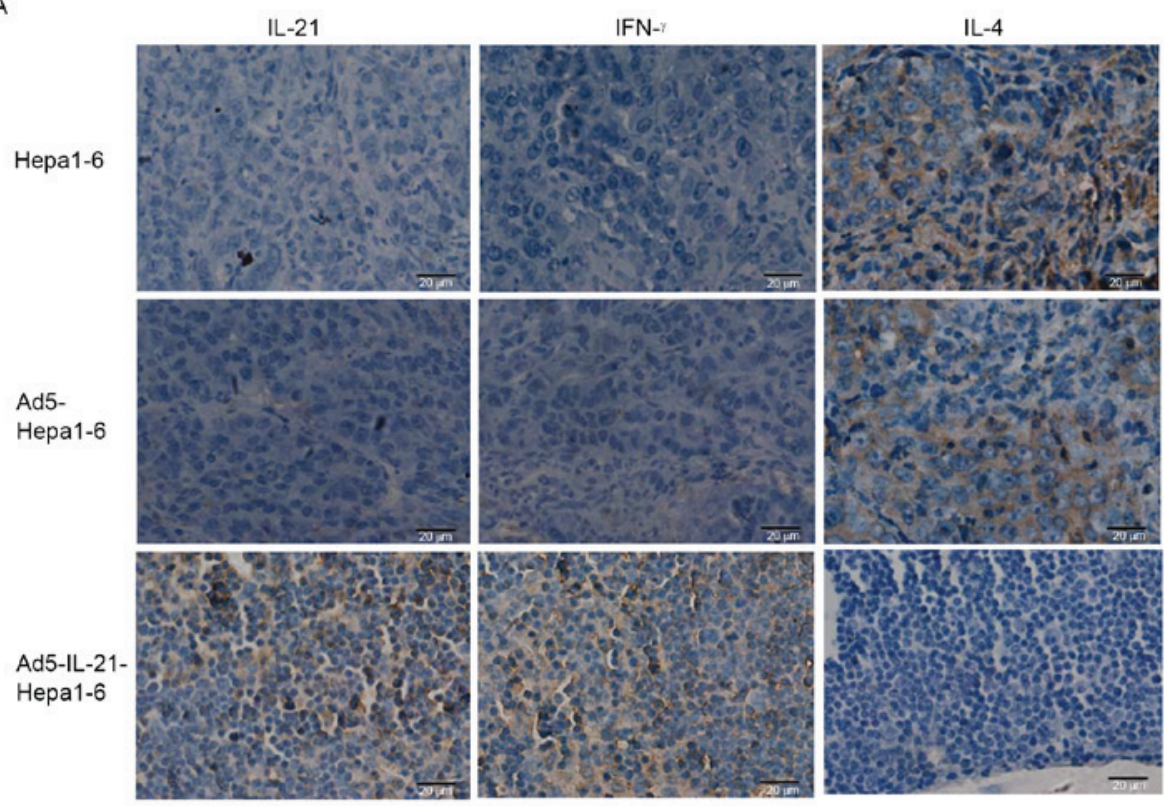

B

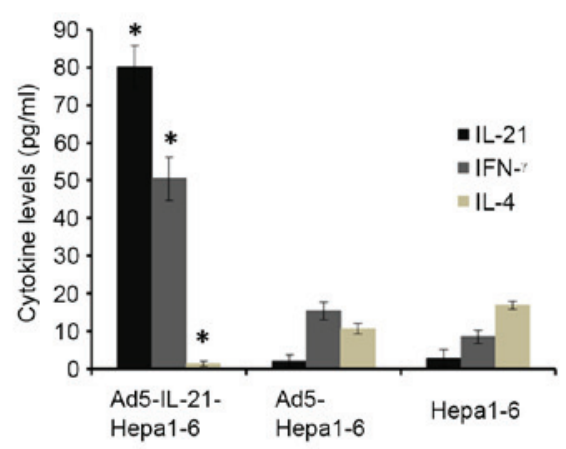

D

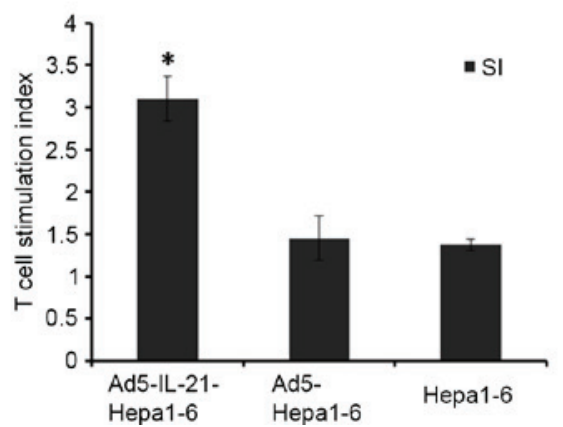

C

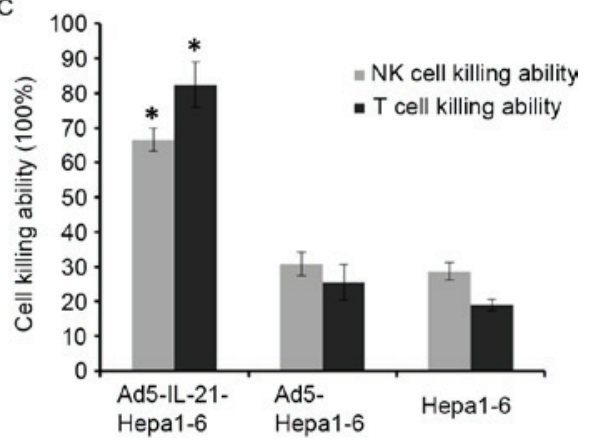

$\mathrm{E}$

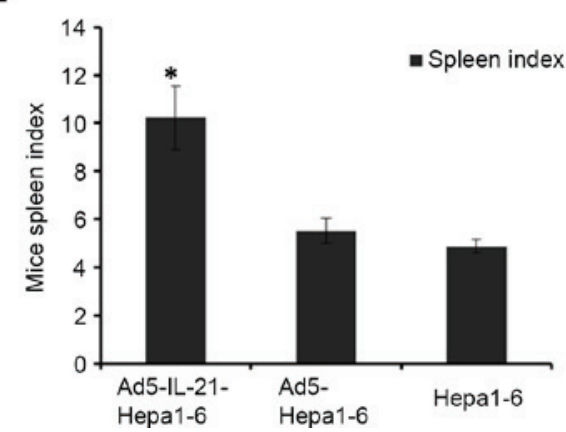

Figure 3. Interleukin 21 (IL-21) enhances antitumor function in mice. (A) Immunohistochemistry confirmed that IL-21 and interferon (IFN)- $\gamma$ levels in Ad5-IL-21-Hepa1-6 mouse tumor tissues were much higher than those in the other two groups. Magnification, x400. (B) Enzyme-linked immunosorbent assay assay results were consistant with those from immunohistochemistry, which confirmed that IL-21 and IFN- $\gamma$ levels in Ad5-IL-21-Hepa1-6 mouse serum were much higher than in the other two groups. (C) NK and T cell killing assay revealed the killing ability of these cells in Ad5-IL-21-Hepa1-6 mouse spleen was much higher than in the other two groups. (D) T cell proliferation assay demonstrated that the T cell proliferation ability in Ad5-IL-21-Hepa1-6 mouse spleen was much higher than in the other two groups. (E) The spleen index of Ad5-IL-21-Hepa1-6 mice was also observed to be significantly higher than that of the other two groups. ${ }^{*} \mathrm{P}<0.05$, compared with Ad5-Hepa1-6 and Hepa1-6 groups.

Using the subcutaneous liver tumor model, we first revealed that IL-21 gene expression in the Hepa1-6 cell line significantly decreases the tumorigenicity of Hepal-6. In the Ad5-IL-21-Hepa1-6 group, only one of the four mice grew a small tumor, and the other three mice did not grow any tumors, while in the Ad5-Hepa1-6 and Hepa1-6 groups, all the mice grew tumors, and the tumor weights and volumes were much larger than in the Ad5-IL-21-Hepa1-6 group. We speculated that this was due to the infection and expression efficiency of
IL-21 mediated by Ad5 compared with naked plasmid injection, as well as the effective strategy we used in our study. This is positive news for vaccine development.

We also observed that the antitumor immune response was significantly enhanced in Ad5-IL-21-Hepa1-6 mice, which is consistent with the results of Pan et al (16) and Cheng et al (17), but the antitumor effect is much better, due to the infection and expression efficiency of IL-21 mediated by Ad5 compared with naked plasmid injection. The killing ability of NK and T cells 
in mouse spleen was significantly enhanced. We also detected high IFN- $\gamma$ and low IL-4 levels in the serum and tumor tissue in the Ad5-IL-21-Hepa1-6 group. Since IFN- $\gamma$ is a typical Th1 cytokine and IL-4 is a typical Th2 cytokine, the results of the present study indicated that IL-21 promoted the immune response shift to a Th1 response in mice, which is superior to the Th2 response for antitumor reactions. These data explain why IL-21 reduced the tumorigenicity of Hepa1-6. Our study is likely to lay a strong foundation for future biological treatments of liver cancer and vaccine development.

\section{Acknowledgements}

This study was supported by grants from the National Natural Science Foundation of China (81373185 and 30901779), the Natural Science Foundation of Shandong, China (ZR2009CM019), Shandong Province Department of Education Foundation of China (J10LF62), Shandong Province Health Department (2013WS0287 and 2014WS0462), and funding from the International Cooperation Program for Excellent Lecturers of 2012 by Shandong Provincial Education Department, China.

\section{References}

1. Parrish-Novak J, Dillon SR, Nelson A, Hammond A, Sprecher C, Gross JA, Johnston J, Madden K, Xu W, West J, et al: Interleukin 21 and its receptor are involved in NK cell expansion and regulation of lymphocyte function. Nature 408: 57-63, 2000.

2. Bryant VL, Ma CS, Avery DT, Li Y, Good KL, Corcoran LM, de Waal Malefyt R and Tangye SG: Cytokine-mediated regulation of human B cell differentiation into Ig-secreting cells: predominant role of IL-21 produced by CXCR 5+T follicular helper cells. J Immunol 179: 8180-8190, 2007.

3. Coquet JM, Kyparissoudis K, Pellicci DG, Besra G, Berzins SP, Smyth MJ and Godfrey DI: IL-21 is produced by NKT cells and modulates NKT cell activation and cytokine production. J Immunol 178: 2827-2834, 2007.

4. Ertelt JM, Johanns TM, Rowe JH and Way SS: Interleukin (IL)-21-independent pathogen-specific $\mathrm{CD} 8^{+} \mathrm{T}$-cell expansion and IL-21-dependent suppression of $\mathrm{CD}^{+}{ }^{+} \mathrm{T}$-cell IL-17 production. Immunology 131: 183-191, 2010.

5. Liu Z, Yang L, Cui Y, Wang X, Guo C, Huang Z, Kan Q, Liu Z and Liu Y: Il-21 enhances NK cell activation and cytolytic activity and induces Th17 cell differentiation in inflammatory bowel disease. Inflamm Bowel Dis 15: 1133-1144, 2009.
6. Ruffin N, Lantto R, Pensieroso S, Sammicheli S, Hejdeman B, Rethi B and Chiodi F: Immune activation and increased IL-21R expression are associated with the loss of memory B cells during HIV-1 infection. J Intern Med 272: 492-503, 2012.

7. Liu W, Dienz O, Roberts B, Moussawi M, Rincon M and Huber SA: IL-21R expression on $\mathrm{CD}^{+} \mathrm{T}$ cells promotes $\mathrm{CD} 8^{+}$ $\mathrm{T}$ cell activation in coxsackievirus B3 induced myocarditis. Exp Mol Pathol 92: 327-333, 2012.

8. Hamming OJ, Kang L, Svensson A, Karlsen JL, Rahbek-Nielsen H, Paludan SR, Hjorth SA, Bondensgaard K and Hartmann R: Crystal structure of interleukin-21 receptor (IL-21R) bound to IL-21 reveals that sugar chain interacting with WSXWS motif is integral part of IL-21R. J Biol Chem 287: 9454-9460, 2012.

9. Hashmi MH and Van Veldhuizen PJ: Interleukin-21: updated review of Phase I and II clinical trials in metastatic renal cell carcinoma, metastatic melanoma and relapsed/refractory indolent non-Hodgkin's lymphoma. Expert Opin Biol Ther 10: 807-817, 2010.

10. Thompson JA, Curti BD, Redman BG, Bhatia S, Weber JS, Agarwala SS, Sievers EL, Hughes SD, DeVries TA and Hausman DF: Phase I study of recombinant interleukin-21 in patients with metastatic melanoma and renal cell carcinoma. J Clin Oncol 26: 2034-2039, 2008.

11. Kesselring R, Jauch D and Fichtner-Feigl S: Interleukin 21 impairs tumor immunosurveillance of colitis-associated colorectal cancer. Oncoimmunology 1: 537-538, 2012.

12. Cao FF, Yu S, Jiang ZY and Bao YX: Diagnostic accuracy of Golgi protein 73 in primary hepatic carcinoma using ELISA: a systematic review and meta-analysis. Clin Lab 60: 587-597, 2014.

13. Dongiovanni P, Romeo S and Valenti L: Hepatocellular carcinoma in nonalcoholic fatty liver: role of environmental and genetic factors. World J Gastroenterol 20: 12945-12955, 2014.

14. Grünwald V, Desar IM, Haanen J, Fiedler W, Mouritzen U, Olsen MW and van Herpen CM: A phase I study of recombinant human interleukin-21 (rIL-21) in combination with sunitinib in patients with metastatic renal cell carcinoma (RCC). Acta Oncol 50: 121-126, 2011.

15. Wood B, Sikdar S, Choi SJ, Virk S, Alhejaily A, Baetz T and LeBrun DP: Abundant expression of interleukin-21 receptor in follicular lymphoma cells is associated with more aggressive disease. Leuk Lymphoma 54: 1212-1220, 2013.

16. Pan XC, Li L, Mao JJ, Yao W, Zheng JN, Liu M and Fu JJ: Synergistic effects of soluble PD-1 and IL-21 on antitumor immunity against $\mathrm{H} 22$ murine hepatocellular carcinoma. Oncol Lett 5: 90-96, 2013.

17. Cheng M,Zhi K, Gao X, He B, Li Y,Han J,Zhang Z and Wu Y: Activation of cellular immunity and marked inhibition of liver cancer in a mouse model following gene therapy and tumor expression of GM-SCF, IL-21, and Rae-1. Mol Cancer 12: 166, 2013. 